\title{
CORRIGENDUM \\ Genetic origin, admixture and population history of aurochs (Bos primigenius) and primitive European cattle
}

\author{
MR Upadhyay, W Chen, JA Lenstra, CRJ Goderie, DE MacHugh, SDE Park, DA Magee, D Matassino, F Ciani, \\ H-J Megens, JAM van Arendonk, MAM Groenen, European Cattle Genetic Diversity Consortium and \\ RPMA Crooijmans
}

Heredity (2017) 119, 469; doi:10.1038/hdy.2017.59; published online 11 October 2017

Correction to: Heredity (2017) 118, 169-176; doi:10.1038/ hdy.2016.79; published online 28 September 2016

Following the publication of this article the authors have noticed an error in the code used for three-population tests which led to change in the results, in particular, for Iberian cattle (revised Supplementary Materials are provided with this correction). Therefore, the below paragraphs should be amended:

In the RESULTS section, the fourth paragraph should be changed from:

Significant negative $\mathrm{f} 3$ statistics with NE zebu as one of the reference populations indicates for the BAI breeds (Busha (BU), Chianina $(\mathrm{CH})$ and Maremana (MA)) a zebu ancestry (Supplementary Table S2). A high number of significant negative f3 statistics (Supplementary Table S3) suggests admixture between regional cattle as is observed for all IBR breeds (except Maronesa). The majority of IBR breeds, Chianina (CH), Jersey (JE), White Park (WP), Fleckvieh (FL), Dutch Belted (DB), Dutch Friesian (DF), MRY and Brown Swiss (BS) exhibits evidence of aurochs ancestry (at least one significant f3 test with aurochs as one of the reference populations, Supplementary Table S4). Non-significant f3 statistics indicate isolated breed structures for the majority of the BRI and NLD breeds (Supplementary Table S4).

To:

Significant negative $\mathrm{f} 3$ statistics with NE zebu as one of the reference populations indicates a zebu ancestry for the BAI breed Busha (BU) (Supplementary Table S2). A high number of significant negative f3 statistics (Supplementary Table S3) suggests admixture between regional cattle, as is observed for some IBR breeds. Only one IBR breed displayed aurochs ancestry. Non-significant $\mathrm{f} 3$ statistics indicate isolated breed structures for all of the BRI and NLD breeds (Supplementary Table S4).

In the DISCUSSION section, result will slightly change from:

The three-population tests (Supplementary Table S4) suggest a well differentiated breed structure for the majority of the BRI and NLD breeds.

To:

The three-population tests (Supplementary Table S4) suggest a well differentiated breed structure for all the BRI and NLD breeds.

It is worth noting that no conclusions have been drawn solely based on the three-population tests. Overall interpretations are also based on PCA, ADMIXTURE, distance based phylogenetic tree, D-statistics and Runs of homozygosity. Hence, these changes do not affect any of the central messages of the paper. All the analysis carried out in the paper remains perfectly reproducible.

The authors wish to apologize for any inconvenience caused.

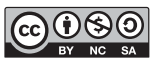

This work is licensed under a Creative Commons Attribution-NonCommercial-ShareAlike 4.0 International License. The images or other third party material in this article are included in the article's Creative Commons license, unless indicated otherwise in the credit line; if the material is not included under the Creative Commons license, users will need to obtain permission from the license holder to reproduce the material. To view a copy of this license, visit http://creativecommons.org/licenses/bync-sa/4.0/

(C) The Author(s) 2017 